\title{
Article \\ Anodal Capture for Multisite Pacing with a Quadripolar Left Ventricular Lead: A Feasibility Study
}

\author{
Alexandre Bodin ${ }^{*}+\left(\mathbb{D}\right.$, Arnaud Bisson $\mathbb{(}^{(}$, Clémentine Andre, Dominique Babuty and Nicolas Clementy \\ Service de Cardiologie, Centre Hospitalier Universitaire Trousseau et EA7505, Faculté de Médecine, Université \\ François Rabelais, 37000 Tours, France; arnaud.bisson37@gmail.com (A.B.); clementine2andre@gmail.com (C.A.); \\ d.babuty@chu-tours.fr (D.B.); N.CLEMENTY@chu-tours.fr (N.C.) \\ * Correspondence: alexandre.bodin@etu.univ-tours.fr; Tel.: +33-2-47-47-46-08 \\ + Current address: Service de Cardiologie, Centre Hospitalier Universitaire Trousseau, \\ 37170 Chambray-Les-Tours, France.
}

Citation: Bodin, A.; Bisson, A.; Andre, C.; Babuty, D.; Clementy, N. Anodal Capture for Multisite Pacing with a Quadripolar Left Ventricular Lead: A Feasibility Study. J. Clin. Med. 2021, 10, 5886. https://doi.org/ $10.3390 / \mathrm{jcm} 10245886$

Academic Editor: Antonio Rapacciuolo

Received: 26 November 2021 Accepted: 13 December 2021 Published: 15 December 2021

Publisher's Note: MDPI stays neutral with regard to jurisdictional claims in published maps and institutional affiliations.

Copyright: (c) 2021 by the authors. Licensee MDPI, Basel, Switzerland. This article is an open access article distributed under the terms and conditions of the Creative Commons Attribution (CC BY) license (https:// creativecommons.org/licenses/by/ $4.0 /)$.

\begin{abstract}
Background: Up to $40 \%$ of patients are CRT non-responders. Multisite pacing, using a unique quadripolar lead, also called multipoint/multipole pacing (MPP), is a potential alternative. We sought to determine the feasibility of intentional anodal capture using a single LV quadripolar lead, to reproduce MPP without the need of a specific algorithm (so-called "pseudo MPP"). Methods: Consecutive patients implanted with a commercially available CRT device and a quadripolar LV lead in our department were prospectively included. The electric charge ( $Q$, in Coulomb) of RV and LV pacing spikes were calculated for all available LV pacing configurations at the threshold. The best MPP was defined as the configuration with the lowest consumption $\left(\mathrm{Q}_{\mathrm{RV}}+\mathrm{Q}_{\mathrm{best} \mathrm{LV} 1}+\right.$ $\left.\mathrm{Q}_{\text {best LV2 }}\right)$. The best "pseudo MPP" $\left(\mathrm{Q}_{\mathrm{RV}}+\mathrm{Q}_{\mathrm{LV} 1-\mathrm{LV} 2 \text { with anodal capture }}\right)$ and best BVp $\left(\mathrm{Q}_{\mathrm{RV}}+\mathrm{Q}_{\text {best } \mathrm{LV}}\right)$ were also calculated. A theoretical longevity was estimated for each configuration at the threshold without a safety margin. Results: A total of 235 configurations were tested in 15 consecutive patients. "Pseudo-MPP" was feasible in $80 \%$ of patients with $3.1 \pm 2.6$ vectors available per-patient and $\mathrm{LV}_{\text {proximal }}-\mathrm{LV}_{\text {distal }}$ (most distant electrodes) vectors were available in $47 \%$ of patients. Each MPP pacing spike electrical charge was comparable to "pseudo-MPP" $(18,428 \pm 6863 \mu \mathrm{C}$ and $20,528 \pm 5509 \mu \mathrm{C}$, respectively, $p=0.15$ ). Theoretical longevity was 6.2 years for MPP, 5.6 years for "pseudo-MPP" and 13.7 years for BVp. Conclusions: "Pseudo MPP" using intentional anodal capture with a quadripolar left ventricular lead, mimicking conventional multisite pacing, is feasible in most of CRT patients, with comparable energy consumption. Further studies on their potential clinical impact are needed.
\end{abstract}

Keywords: cardiac resynchronization therapy; multipoint pacing; multisite pacing; anodal capture

\section{Introduction}

Cardiac resynchronization therapy (CRT) in heart failure showed a diminution of mortality and morbidity [1-6]. However, up to $40 \%$ of patients are non-responders to CRT [2,7-9].

The initial concept of LV multisite pacing (MSp) emerged in this context and showed that pacing using $2 \mathrm{LV}$ leads was associated with improved LV reverse remodeling, as compared with standard biventricular pacing (BVp) [10], especially in cases of a posterolateral scar [11]. MSp through a single quadripolar lead (using 2 pacing cathodes out of 4 electrodes), also called multipoint/multipole pacing (MPP), is a safer and easier technique [12-14], which showed an improvement in hemodynamics and the functional status but remains debated and still needs more morbimortality evidence, especially through programming with large anatomical separation [15-23]. Other limitations include a faster battery drain [24] and the need for a dedicated mode that is programmable within the device software. 
Anodal capture results, during bipolar pacing, from a high density current from the cathode allows for the capturing of the myocardium near the anode. Depolarization arises from both the anode and the cathode of the used electrical bipole. Intentional anodal capture during bipolar pacing by the LV quadripolar lead, so-called "pseudo-MPP" (Figure 1), may have an acute hemodynamic benefit equal to conventional MPP [25,26].

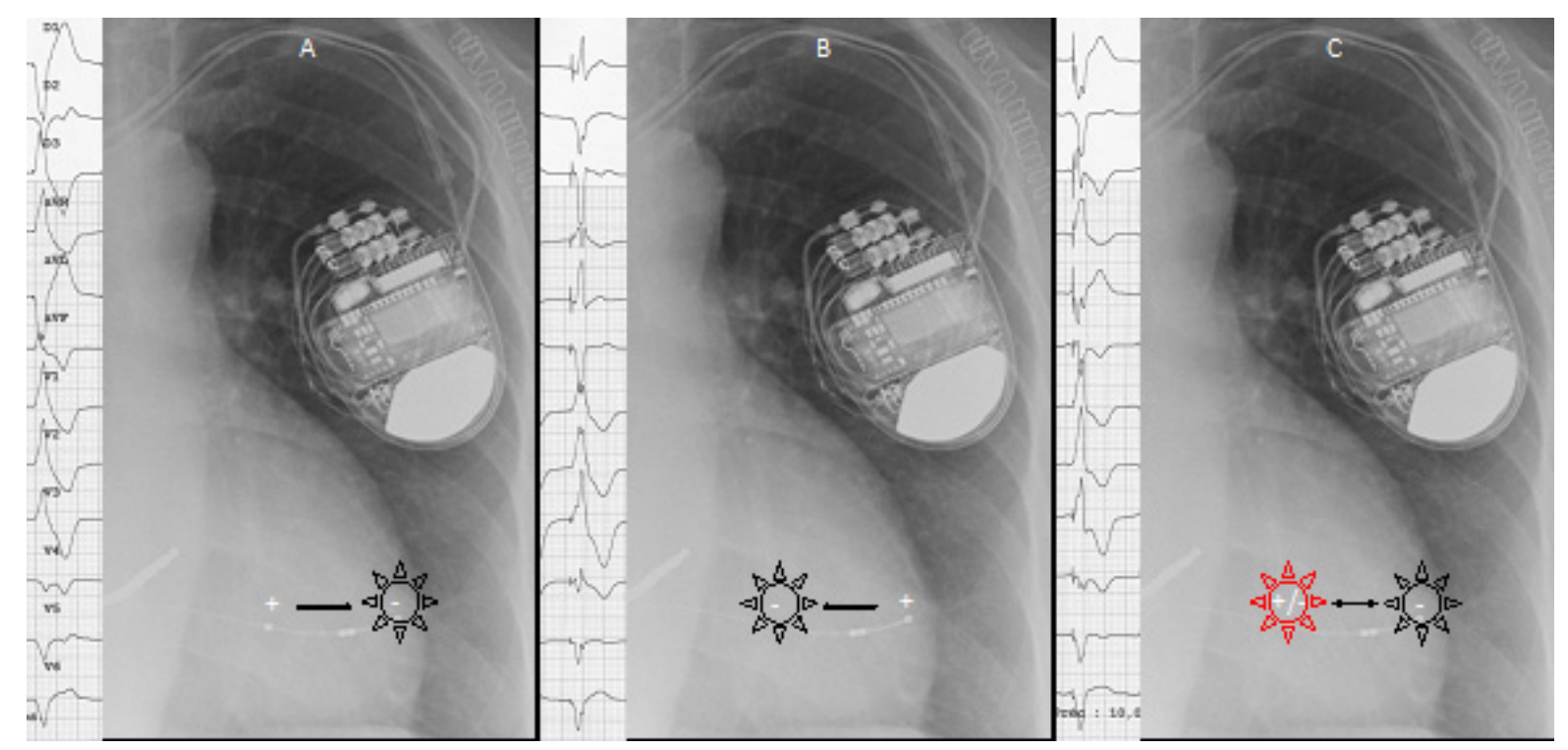

Figure 1. Intentional anodal capture during bipolar pacing by the LV quadripolar lead, so-called "pseudo-MPP". During conventional bipolar pacing, depolarization wave front arise from the cathode $(-)(\mathbf{A}, \mathbf{B})$. When a high-density current is applied, anodal capture may be achieved, and depolarization wavefront arises from both the anode (-) and the cathode $(+)$ of electrical bipole. The resulting QRS complex (left panels) is a fusion between anodal and cathodal pacing (C).

We sought to determine the feasibility of the intentional anodal capture using a single LV quadripolar lead, to reproduce MPP without the need for a specific algorithm.

\section{Methods}

Consecutive patients implanted with a CRT device and a quadripolar LV lead in our department were prospectively included. Commercially available MPP-capable CRT device from Abbott ${ }^{\circledR}$ (Chicago, IL, USA), Boston Scientific ${ }^{\circledR}$ (Marlborough, MA, USA) and Medtronic ${ }^{\circledR}$ (Dublin, Ireland) were used.

Enrolled patients provided oral informed consent and data were collected in accordance with institutional guidelines on ethics.

Electrical and ECG tests were performed after implantation. Threshold and impedance were manually measured in each programmable LV configuration. The pacing duration was 0.4 milliseconds. "Pseudo-MPP" stimulation was identified by a QRS morphology resulting from the fusion of the unipolar-cathode paced QRS complex and the unipolaranode paced QRS complex. Its threshold was identified using an LV true bipolar vector decremental threshold test (Figure 2). Vectors with phrenic nerve stimulation (PNS) were not considered. When no ECG difference was observed, either because of absence of "pseudo-MPP" or due to a significant difference of morphology between cathodal and anodal pacing, the vector was not considered. 


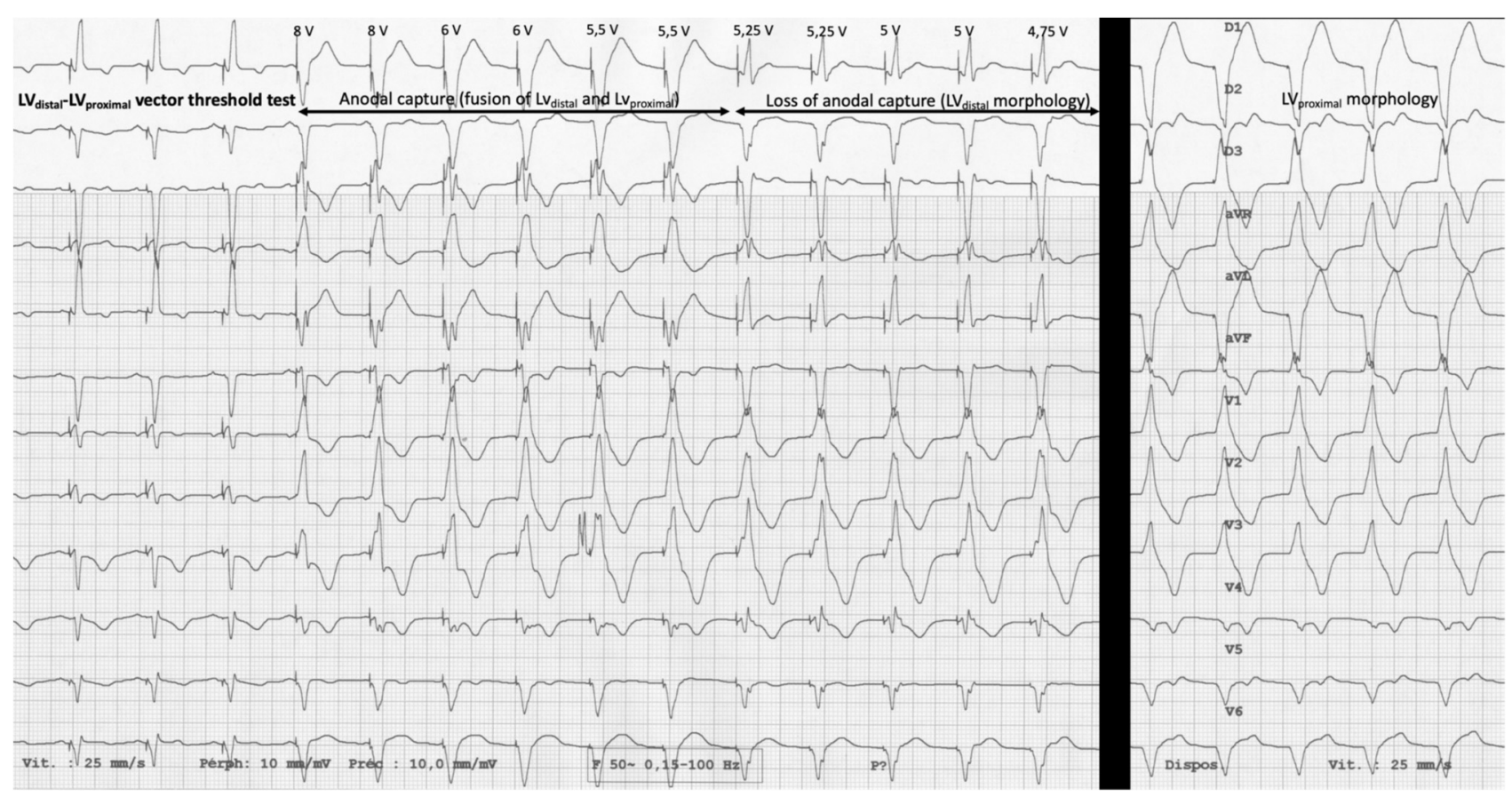

Figure 2. "Pseudo MPP" threshold measurement. Example with $L_{\text {distal }}-\mathrm{LV}_{\text {proximal }}$ vector threshold test with an impulsion duration of $0.4 \mathrm{~ms}$. An abrupt change in QRS morphology can be identified between $5.5 \mathrm{~V}$ and $5.25 \mathrm{~V}, 5.5 \mathrm{~V}$ being considered as the "pseudo-MPP" threshold. "Pseudo-MPP" QRS morphology results from the fusion of mono-LVPdistal and mono-LVp proximal QRS morphologies.

\section{Theoretical Battery Drain at the Threshold}

Using the data of the threshold tests, the electric charge (Q, in Coulomb) of the RV and LV pacing spikes were calculated for all available LV-pacing configurations at the threshold at $0.4 \mathrm{~ms}$ (without any safety margin). The first LV vector for MPP was named LV1, the second was named LV2. The best MPP was defined as the configuration with the lowest consumption $\left(\mathrm{Q}_{\mathrm{RV}}+\mathrm{Q}_{\text {best LV1 }}+\mathrm{Q}_{\text {best LV2 }}\right)$. The best "pseudo MPP" $\left(\mathrm{Q}_{\mathrm{RV}}+\mathrm{Q}_{\mathrm{LV} 1-\mathrm{LV} 2 \text { with anodal capture }}\right)$ and best BVp $\left(\mathrm{Q}_{\mathrm{RV}}+\mathrm{Q}_{\text {best } \mathrm{LV}}\right)$ were also calculated. $\mathrm{A}$ theoretical longevity was estimated for best BVp, best MPP and best "pseudo-MPP" configurations in order to compare the battery drain. We considered permanent (100\%) RV and LV pacing at 60 beats per minute in the VVI mode without atrial pacing, without any electrical shock, at the threshold without a safety margin, with a pacing duration of $0.4 \mathrm{~ms}$, and a usable capacity of $1000 \mathrm{mAh}$.

After all tests were performed, the device was programmed according to the standard practice.

\section{Statistical Analyses}

All statistical analyses were performed using JMP ${ }^{\circledR}$ 9.0.1. software (SAS Institute Inc., Cary, NC, USA). Qualitative variables are described using counts and percentages and continuous quantitative variables as mean \pm standard deviation. Comparisons between MPP, pseudo-MPP and BVp were performed using non-parametric tests. Statistical significance was assumed at $p<0.05$.

\section{Results}

A total of 235 configurations were tested in 15 consecutive patients ( 5 with an Abbott ${ }^{\circledR}$, 5 with a Boston ${ }^{\circledR}$ and 5 with a Medtronic ${ }^{\circledR}$ device).

The baseline characteristics are described in Table 1. Patients were $72 \pm 11$ years old, $67 \%$ were male, $40 \%$ had ischemic heart disease, $60 \%$ had a left bundle branch block 
morphology, the mean intrinsic QRS duration was $137 \pm 27 \mathrm{~ms}$ and the mean left ventricular ejection fraction (LVEF) was $28 \pm 6 \%$.

Table 1. Baseline characteristics.

\begin{tabular}{lc}
\hline Patients, $n$ & $\mathbf{1 5}$ \\
\hline Age, years & $72 \pm 11$ \\
Male sex, $n(\%)$ & $10(67 \%)$ \\
Ischemic heart disease, $n(\%)$ & $6(40 \%)$ \\
Hypertension, $n(\%)$ & $8(53 \%)$ \\
Diabetes mellitus, $n(\%)$ & $4(27 \%)$ \\
Sinus rythm, $n(\%)$ & $13(87 \%)$ \\
LBBB, $n(\%)$ & $9(60 \%)$ \\
QRS duration (ms) & $137 \pm 27$ \\
LVEF (\%) & $28 \pm 6$ \\
LVEDD (mm) & $58 \pm 6$ \\
Device & \\
Abbott, $n$ & 5 \\
Boston, $n$ & 5 \\
Medtronic, $n$ & 5 \\
Quadripolar lead & \\
Abbott's Quartet, $n(\%)$ & $3(20 \%)$ \\
Boston's Acuity, $n(\%)$ & $4(27 \%)$ \\
Medtronic's Attain, $n(\%)$ & $8(53 \%)$ \\
\hline
\end{tabular}

LBBB: Left bundle branch block, LVEF: left ventricular ejection fraction, LVEDD: Left ventricular end-diastolic diameter.

Pacing characteristics are described in Table 2. The final LV lead location was lateral in $47 \%$ of patients. "Pseudo-MPP" was feasible in $80 \%$ of patients, with $3.1 \pm 2.6$ vectors available per patient (35\% of all LV bipolar vectors, i.e., $47 / 135)$. "Pseudo-MPP" with $\mathrm{LV}_{\text {proximal }}-\mathrm{LV}_{\text {distal }}$ (most distant electrodes) vectors was available in $47 \%$ of patients ( $45 \%$ of the vectors, i.e., 9/20). The mean "pseudo-MPP" threshold was $5.2 \pm 0.9$ V. Only two vectors with PNS during the "pseudo-MPP" test were excluded.

Table 2. Pacing characteristics.

\begin{tabular}{lc}
\hline Final LV lead location & \\
Anterior, $n(\%)$ & $1(6 \%)$ \\
Anterior-lateral, $n(\%)$ & $4(27 \%)$ \\
Lateral, $n(\%)$ & $7(47 \%)$ \\
Posterior-lateral, $n(\%)$ & $2(14 \%)$ \\
Posterior, $n(\%)$ & $1(6 \%)$ \\
Mean LV threshold (V) & $2.2 \pm 0.8$ \\
Best LV threshold (V) & 0.9 \\
Mean LV vector impedance (Ohm) & $731 \pm 309$ \\
Available "pseudo MPP" vectors, $n$ & $3.1 \pm 2.6$ \\
Mean "pseudo MPP" threshold (V) & $5.2 \pm 0.9$ \\
Mean LV1 threshold when "pseudo MPP" available (V) & $2 \pm 0.6$ \\
Mean LV2 Threshold when "pseudo MPP" available (V) & $1.6 \pm 0.5$
\end{tabular}

LV: left ventricular, LV1: first LV vector, LV2: second LV vector, MPP: multipoint/multipole pacing.

At the threshold without a safety margin, at $0.4 \mathrm{~ms}$, each MPP pacing spike electrical charge was comparable to "pseudo-MPP" $(18,428 \pm 6863 \mu \mathrm{C}$ and 20,528 $\pm 5509 \mu \mathrm{C}$, respectively, $p=0.15$ ). The theoretical longevity was 6.2 years for MPP, 5.6 years for "pseudo-MPP" and 13.7 years for BVp (Table 3). 
Table 3. Mean Electrical charge $(\mu \mathrm{C})$ and theoretical longevity (years) at the threshold without safety margin.

\begin{tabular}{lccc}
\hline & Best & Best & Best \\
& MPP & "Pseudo MPP" & BVp \\
\hline Electrical charge $(\mu \mathrm{C})$ & $18,428 \pm 6863$ & $20,528 \pm 5509 \int$ & $8357 \pm 2307 \ddagger$ \\
Longevity (years) & 6.2 & 5.6 & 13.7 \\
\hline
\end{tabular}

MPP: multipoint/multipole pacing, BVp: biventricular pacing. $\int p=0.15$ best "pseudo MPP" versus best MPP, $\ddagger p=0.0005$ best BVp versus best MPP and best "pseudo MPP".

The mean RV electrical charge was $3788 \pm 1300 \mu \mathrm{C}$, representing $20.6 \%$ for MPP, $18.5 \%$ for "pseudo-MPP" and $45.3 \%$ for BVp, of the total biventricular electrical charge.

\section{Discussion}

In this pilot study, the main results were: (1) "pseudo-MPP" is feasible in $80 \%$ of patients, in almost half of the patients when using the most distant electrodes; (2) "pseudoMPP" and MPP energy consumptions are comparable.

Dell'Era et al. enrolled 30 CRT patients and tested, during the implantation procedure, the anodal capture on quadripolar leads from the three main manufacturers, using a Medtronic pacing-sensing analyzer [27].

Conversely, we evaluated the feasibility of "pseudo-MPP" after implantation using the implanted CRT devices algorithms. They found an anodal capture in $93 \%$ of the patients, with a maximum pacing impulsion of $10 \mathrm{~V}$ at $0.5 \mathrm{~ms}$, a much higher value than the one programmable in "real life", explaining the lower $80 \%$ rate in our study. The mean anodal capture threshold was $3.9 \pm 2.4 \mathrm{~V}$ at $0.5 \mathrm{~ms}(5.2 \pm 0.9 \mathrm{~V}$ at $0.4 \mathrm{~ms}$ in our study) and the mean cathodal capture threshold was $1.9 \pm 1.6 \mathrm{~V}$ at $0.5 \mathrm{~ms}(2.2 \pm 0.8 \mathrm{~V}$ at $0.4 \mathrm{~ms}$ in our study), which was found to be comparable in both studies.

"Pseudo MPP" has several advantages. It allows for MPP in MPP incompatible devices. Anodal capture is also associated with absence of intraventricular delay (0 ms), which could be useful in devices with a minimum programmable delay ( $5 \mathrm{~ms}$ for Abbott and $10 \mathrm{~ms}$ for Medtronic for example), and may achieve a better resynchronization [21].

We do not provide data on any hemodynamics improvement. Morishima et al. showed an acute improvement on $\mathrm{dP} / \mathrm{dT}$ max during "pseudo-MPP" comparable to MPP [25].

The benefits of MPP and more so of "pseudo-MPP" remain unclear, and acute hemodynamics improvement does not predict the long-term response and/or clinical outcomes.

\section{Limitations}

Anodal capture is time consuming, necessitating a 12-lead electrocardiogram and a manual threshold test, which may be difficult to perform routinely. Very limited changes in the QRS morphology during "pseudo-MPP" threshold tests were observed in a few cases, with a difficult determination of the true "pseudo-MPP" threshold and probably limited effects on the depolarization wavefront and resynchronization.

"Pseudo-MPP" and MPP are associated with rapid battery depletion as compared with conventional $\mathrm{BVp}$. Indeed, the battery drain was about twice the difference versus $\mathrm{BVp}$. A prospective study of the selected patients would be interesting in order to detect potential clinical impact. However, high battery drain would be associated with frequent generator changes and associated risks (infectious for example). In our opinion, only non-responder patients to CRT could ethically be included by comparing the best BVp versus MPP and "pseudo-MPP".

\section{Conclusions}

"Pseudo MPP", using intentional anodal capture with a quadripolar left ventricular lead, mimicking conventional multisite pacing, is feasible in most CRT patients, with a comparable energy consumption.

Further studies on the potential clinical impact are needed. 
Author Contributions: Conceptualization, A.B. (Alexandre Bodin), A.B. (Arnaud Bisson), C.A., D.B. and N.C.; methodology, A.B. (Alexandre Bodin), A.B. (Arnaud Bisson), C.A., D.B. and N.C.; software, A.B. (Alexandre Bodin) and N.C.; validation, A.B. (Alexandre Bodin), A.B. (Arnaud Bisson), C.A., D.B. and N.C.; formal analysis, A.B. (Alexandre Bodin) and N.C.; investigation, A.B. (Alexandre Bodin), A.B. (Arnaud Bisson), C.A., D.B. and N.C.; writing-original draft preparation, A.B. (Alexandre Bodin) and N.C.; writing-review and editing, A.B. (Alexandre Bodin), A.B. (Arnaud Bisson), C.A., D.B. and N.C.; visualization, A.B. (Alexandre Bodin) and N.C.; supervision, A.B. (Alexandre Bodin), A.B. (Arnaud Bisson), C.A., D.B. and N.C.; project administration, A.B. (Alexandre Bodin) and N.C. All authors have read and agreed to the published version of the manuscript.

Funding: This research received no external funding.

Informed Consent Statement: Informed consent was obtained from all subjects involved in the study.

Data Availability Statement: Data is contained within the article.

Conflicts of Interest: D.B: speaker for BMS/Pfizer and Medtronic. N.C: consultant or speaker for Boston Scientific and Medtronic. Other authors-no conflict of interest.

$\begin{array}{ll}\text { Abbreviations } \\ \text { AV } & \text { atrio-ventricular } \\ \text { BVp } & \text { biventricular pacing } \\ \text { CRT } & \text { cardiac resynchronization therapy } \\ \text { LV1 } & \text { first LV vector } \\ \text { LV2 } & \text { second LV vector } \\ \text { LVp } & \text { left ventricle paced } \\ \text { LVs } & \text { left ventricle sensed } \\ \text { MPP } & \text { multipoint/multipole pacing } \\ \text { MSp } & \text { multisite pacing } \\ \text { PNS } & \text { phrenic nerve stimulation } \\ \text { PVC } & \text { premature ventricular complexe } \\ \text { Q } & \text { electrical charge } \\ \text { RVp } & \text { right ventricle paced } \\ \text { RVs } & \text { right ventricle sensed }\end{array}$

\section{References}

1. Abraham, W.T.; Fisher, W.G.; Smith, A.L.; Delurgio, D.B.; Leon, A.R.; Loh, E.; Kocovic, D.Z.; Packer, M.; Clavell, A.L.; Hayes, D.L.; et al. Cardiac Resynchronization in Chronic Heart Failure. N. Engl. J. Med. 2002, 346, 1845-1853. [CrossRef]

2. Young, J.B.; Abraham, W.T.; Smith, A.L.; Leon, A.R.; Lieberman, R.; Wilkoff, B.; Canby, R.C.; Schroeder, J.S.; Liem, L.B.; Hall, S.; et al. Combined Cardiac Resynchronization and Implantable Cardioversion Defibrillation in Advanced Chronic Heart Failure: The MIRACLE ICD Trial. JAMA 2003, 289, 2685-2694. [CrossRef]

3. Bristow, M.R.; Saxon, L.A.; Boehmer, J.; Krueger, S.; Kass, D.A.; De Marco, T.; Carson, P.; DiCarlo, L.; DeMets, D.; White, B.G.; et al. Cardiac-Resynchronization Therapy with or without an Implantable Defibrillator in Advanced Chronic Heart Failure. N. Engl. J. Med. 2004, 350, 2140-2150. [CrossRef]

4. Moss, A.J.; Hall, W.J.; Cannom, D.S.; Klein, H.; Brown, M.W.; Daubert, J.P.; Estes, N.A.M.; Foster, E.; Greenberg, H.; Higgins, S.L.; et al. Cardiac-Resynchronization Therapy for the Prevention of Heart-Failure Events. N. Engl. J. Med. 2009, 361, 1329-1338. [CrossRef]

5. Tang, A.S.L.; Wells, G.A.; Talajic, M.; Arnold, M.O.; Sheldon, R.; Connolly, S.; Hohnloser, S.H.; Nichol, G.; Birnie, D.H.; Sapp, J.L.; et al. Cardiac-Resynchronization Therapy for Mild-to-Moderate Heart Failure. N. Engl. J. Med. 2010, 363, 2385-2395. [CrossRef]

6. Linde, C.; Gold, M.R.; Abraham, W.T.; St John Sutton, M.; Ghio, S.; Cerkvenik, J.; Daubert, C. REsynchronization reVErses Remodeling in Systolic left vEntricular dysfunction Study Group Long-Term Impact of Cardiac Resynchronization Therapy in Mild Heart Failure: 5-Year Results from the REsynchronization ReVErses Remodeling in Systolic Left VEntricular Dysfunction (REVERSE) Study. Eur. Heart J. 2013, 34, 2592-2599. [CrossRef] [PubMed]

7. Birnie, D.H.; Tang, A.S. The Problem of Non-Response to Cardiac Resynchronization Therapy. Curr. Opin. Cardiol. 2006, 21, 20-26. [CrossRef] [PubMed]

8. Chung, E.S.; Leon, A.R.; Tavazzi, L.; Sun, J.-P.; Nihoyannopoulos, P.; Merlino, J.; Abraham, W.T.; Ghio, S.; Leclercq, C.; Bax, J.J.; et al. Results of the Predictors of Response to CRT (PROSPECT) Trial. Circulation 2008, 117, 2608-2616. [CrossRef] [PubMed] 
9. Auricchio, A.; Prinzen, F.W. Non-Responders to Cardiac Resynchronization Therapy: The Magnitude of the Problem and the Issues. Circ. J. Off. J. Jpn. Circ. Soc. 2011, 75, 521-527. [CrossRef] [PubMed]

10. Leclercq, C.; Gadler, F.; Kranig, W.; Ellery, S.; Gras, D.; Lazarus, A.; Clémenty, J.; Boulogne, E.; Daubert, J.-C.; TRIP-HF (Triple Resynchronization in Paced Heart Failure Patients) Study Group. A Randomized Comparison of Triple-Site versus Dual-Site Ventricular Stimulation in Patients with Congestive Heart Failure. J. Am. Coll. Cardiol. 2008, 51, 1455-1462. [CrossRef]

11. Ginks, M.R.; Duckett, S.G.; Kapetanakis, S.; Bostock, J.; Hamid, S.; Shetty, A.; Ma, Y.; Rhode, K.S.; Carr-White, G.S.; Razavi, R.S.; et al. Multi-Site Left Ventricular Pacing as a Potential Treatment for Patients with Postero-Lateral Scar: Insights from Cardiac Magnetic Resonance Imaging and Invasive Haemodynamic Assessment. Europace 2012, 14, 373-379. [CrossRef] [PubMed]

12. Rogers, D.P.S.; Lambiase, P.D.; Lowe, M.D.; Chow, A.W.C. A Randomized Double-Blind Crossover Trial of Triventricular versus Biventricular Pacing in Heart Failure. Eur. J. Heart Fail. 2012, 14, 495-505. [CrossRef]

13. Lenarczyk, R.; Kowalski, O.; Sredniawa, B.; Pruszkowska-Skrzep, P.; Mazurek, M.; Jędrzejczyk-Patej, E.; Woźniak, A.; Pluta, S.; Głowacki, J.; Kalarus, Z. Implantation Feasibility, Procedure-Related Adverse Events and Lead Performance during 1-Year Follow-up in Patients Undergoing Triple-Site Cardiac Resynchronization Therapy: A Substudy of TRUST CRT Randomized Trial. J. Cardiovasc. Electrophysiol. 2012, 23, 1228-1236. [CrossRef] [PubMed]

14. Bordachar, P.; Gras, D.; Clementy, N.; Defaye, P.; Mondoly, P.; Boveda, S.; Anselme, F.; Klug, D.; Piot, O.; Sadoul, N.; et al. Clinical Impact of an Additional Left Ventricular Lead in Cardiac Resynchronization Nonresponders: The V3trial. Heart Rhythm 2017, 15, 870-876. [CrossRef] [PubMed]

15. Menardi, E.; Ballari, G.P.; Goletto, C.; Rossetti, G.; Vado, A. Characterization of Ventricular Activation Pattern and Acute Hemodynamics during Multipoint Left Ventricular Pacing. Heart Rhythm 2015, 12, 1762-1769. [CrossRef]

16. Pappone, C.; Ćalović, Ž.; Vicedomini, G.; Cuko, A.; McSpadden, L.C.; Ryu, K.; Jordan, C.D.; Romano, E.; Baldi, M.; Saviano, M.; et al. Improving Cardiac Resynchronization Therapy Response with Multipoint Left Ventricular Pacing: Twelve-Month Follow-up Study. Heart Rhythm 2015, 12, 1250-1258. [CrossRef]

17. Osca, J.; Alonso, P.; Cano, O.; Andrés, A.; Miro, V.; Tello, M.J.S.; Olagüe, J.; Martínez, L.; Salvador, A. The Use of Multisite Left Ventricular Pacing via Quadripolar Lead Improves Acute Haemodynamics and Mechanical Dyssynchrony Assessed by Radial Strain Speckle Tracking: Initial Results. EP Europace 2016, 18, 560-567. [CrossRef]

18. Tomassoni, G.; Baker, J.; Corbisiero, R.; Love, C.; Martin, D.; Sheppard, R.; Worley, S.J.; Lee, K.; Niazi, I.; MPP Investigators. Rationale and Design of a Randomized Trial to Assess the Safety and Efficacy of MultiPoint Pacing (MPP) in Cardiac Resynchronization Therapy: The MPP Trial. Ann. Noninvasive Electrocardiol. 2017, 22, e12448. [CrossRef]

19. Zanon, F.; Marcantoni, L.; Baracca, E.; Pastore, G.; Lanza, D.; Fraccaro, C.; Picariello, C.; Conte, L.; Aggio, S.; Roncon, L.; et al. Optimization of Left Ventricular Pacing Site plus Multipoint Pacing Improves Remodeling and Clinical Response to Cardiac Resynchronization Therapy at 1 Year. Heart Rhythm 2016, 13, 1644-1651. [CrossRef]

20. Forleo, G.B.; Santini, L.; Giammaria, M.; Potenza, D.; Curnis, A.; Calabrese, V.; Ricciardi, D.; D’agostino, C.; Notarstefano, P.; Ribatti, V.; et al. Multipoint Pacing via a Quadripolar Left-Ventricular Lead: Preliminary Results from the Italian Registry on Multipoint Left-Ventricular Pacing in Cardiac Resynchronization Therapy (IRON-MPP). Europace 2017, 19, 1170-1177. [CrossRef]

21. Niazi, I.; Baker, J.; Corbisiero, R.; Love, C.; Martin, D.; Sheppard, R.; Worley, S.J.; Varma, N.; Lee, K.; Tomassoni, G.; et al. Safety and Efficacy of Multipoint Pacing in Cardiac Resynchronization Therapy: The MultiPoint Pacing Trial. JACC Clin. Electrophysiol. 2017, 3, 1510-1518. [CrossRef] [PubMed]

22. Bodin, A.; Bisson, A.; Andre, C.; Pierre, B.; Fauchier, L.; Babuty, D.; Clementy, N. Multisite Pacing via a Quadripolar Lead for Cardiac Resynchronization Therapy. J. Interv. Card. Electrophysiol. 2019, 56, 117-125. [CrossRef]

23. Leclercq, C.; Burri, H.; Curnis, A.; Delnoy, P.P.; Rinaldi, C.A.; Sperzel, J.; Lee, K.; Calò, L.; Vicentini, A.; Concha, J.F.; et al. Cardiac Resynchronization Therapy Non-Responder to Responder Conversion Rate in the More Response to Cardiac Resynchronization Therapy with MultiPoint Pacing (MORE-CRT MPP) Study: Results from Phase I. Eur. Heart J. 2019, 40, 2979-2987. [CrossRef] [PubMed]

24. Akerström, F.; Narváez, I.; Puchol, A.; Pachón, M.; Martín-Sierra, C.; Rodríguez-Mañero, M.; Rodríguez-Padial, L.; Arias, M.A. Estimation of the Effects of Multipoint Pacing on Battery Longevity in Routine Clinical Practice. Europace 2018, 20, $1161-1167$. [CrossRef] [PubMed]

25. Morishima, I.; Tomomatsu, T.; Morita, Y.; Tsuboi, H. Intentional Anodal Capture of a Left Ventricular Quadripolar Lead Enhances Resynchronization Equally with Multipoint Pacing. HeartRhythm Case Rep. 2015, 1, 386-388. [CrossRef]

26. Occhetta, E.; Dell'Era, G.; Giubertoni, A.; Magnani, A.; Rametta, F.; Blandino, A.; Magnano, V.; Malacrida, M.; Marino, P. Occurrence of Simultaneous Cathodal-Anodal Capture with Left Ventricular Quadripolar Leads for Cardiac Resynchronization Therapy: An Electrocardiogram Evaluation. EP Europace 2016, 19, 596-601. [CrossRef]

27. Dell'Era, G.; De Vecchi, F.; Prenna, E.; Devecchi, C.; Degiovanni, A.; Malacrida, M.; Magnani, A.; Occhetta, E.; Marino, P. Feasibility of Cathodic-Anodal Left Ventricular Stimulation for Alternative Multisite Pacing. Pacing Clin. Electrophysiol. PACE 2018, 41, 597-602. [CrossRef] 